Research Article

\title{
Finite Element-Based Simulation of Cooling Rate on the Material Properties of an Automobile Silent Block
}

\author{
Burak Öztürk ${ }^{1}$ and Fuat Kara $\mathbb{i D}^{2}$ \\ ${ }^{1}$ Metallurgy and Materials Engineering, Bilecik Seyh Edebali University, Bilecik, Turkey \\ ${ }^{2}$ Mechanical Engineering, Düzce University, Düzce, Turkey \\ Correspondence should be addressed to Fuat Kara; fuatkara@duzce.edu.tr
}

Received 10 April 2020; Revised 7 June 2020; Accepted 8 June 2020; Published 30 June 2020

Academic Editor: Aniello Riccio

Copyright $(2020$ Burak Öztürk and Fuat Kara. This is an open access article distributed under the Creative Commons Attribution License, which permits unrestricted use, distribution, and reproduction in any medium, provided the original work is properly cited.

\begin{abstract}
The aluminum silent block is the part that connects the front suspension mounting and the road wheels. These products are used in high-speed cars and are subject to high engineering stresses. Over time, fractures occur in the connection part of these products due to insufficient strength. These problems are related to production metallurgy, which led to the concept of this study. During mass production, these parts are manufactured using the aluminum extrusion method. In this study, a rapid cooling process using water was applied, with the aim of improving the mechanical properties of the connecting part exposed to high dynamic loads. Samples were taken from the regions of these products which differed in thickness and width, and microhardness and tensile tests were performed for each region. The effects of both the extrusion cooling rate and the regional flash cooling on the material properties were then characterized. As a result of the isothermal transformation, the grain size in the microstructure of the material had shrunk. According to the findings, in this type of production, an average increase in strength of $25 \%$ was observed in the parts of the material subjected to maximum stress. The stress and safety coefficient values were found using finite element analysis, and curves were then drawn showing the differences in the safety coefficient values from the different points. As a result of cooperation between university and industry, the material and mechanical properties of an automobile part were improved in this study. This research has shown that, in terms of the accuracy of the results, it is very important to consider the variations in different regions of the product when defining the mechanical properties of any material produced by applying casting, heat treatment, and plastic forming methods.
\end{abstract}

\section{Introduction}

The suspension system is the name given to all the elements connecting the wheels of a vehicle to its body parts. The main task of the system is to provide roadholding and vehicle safety. The automobile silent block is also part of the suspension system $[1,2]$. The silent block part in the suspension system of a car is shown in Figure 1. When designing a vehicle suspension system, it is necessary to have a good understanding of the consequences of all its parameters. There are two objectives when designing the suspension system. The first is to provide physical and mental comfort and to minimize harm to the passengers inside the vehicle, and the second is to ensure that the road contact force of the vehicle does not change, i.e., to provide good road control [3]. The mechanical capability of the vehicle elements should be taken into consideration when creating this design. The suspension mountings that connect the wheels to the chassis of the vehicle must be resistant to various strains [4].

The most loaded part of the suspension of a vehicle has been discussed. 3D numerical analysis of the silent block was carried out on the basis of the model by using two types of rubber bushings with different hardness [2]. The aim of this work is to achieve experimental data for the improvement of mathematical models of vehicle silent blocks to develop a method for their diagnosis [5]. In a study, the dynamic behavior of an arm-free suspension for an automobile was investigated. A mathematical model based on the vector matrix algebra was used to describe the mechanical system [6]. The results obtained from the numerical experiments revealed 


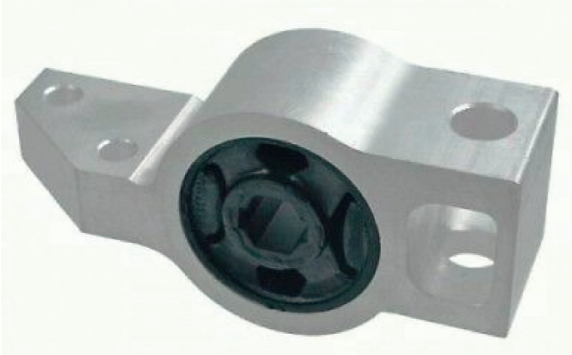

FIgURE 1: Silent block suspension system of a vehicle.

the laws of motion, natural frequencies, and accelerations of the strings and nonstiff masses. These parts need to be replaced because they are exposed to various forces in cars and are also used in aircraft. These are replaced in aircraft because of the deterioration of the elastomeric isolators. Failure of these is caused by the radial load and axial displacement leading to wear and fatigue [7].

The silent block is fixed on the chassis by means of bushings, which allow freedom of rotation to the driving axle of the vehicle. The silent block, which is among the very important parts of an automobile, is itself composed of important parts [4]. The silent block bushing is one of these parts. The outer diameter of the bushing is surrounded by the silent block, which allows the bushing to be connected to the lower frame and to absorb some of the incoming stresses. As a result of these stresses, fatigue cracks and fractures occur in the silent block parts over time.

Silent block connection parts are generally produced by extrusion, which is a plastic forming method used in mass production. Extrusion is a metal forming method in which a billet produced by casting is forced to pass through a mold inside a cylindrical sleeve [8-11]. Extrusion is a method in which lighter metals are processed economically. The extrusion method has gained importance with the development of the aircraft industry. Due to the advantages of this method, its demand has increased among building and architectural designers. It is possible to obtain an economical and desirable product with this method [12].

Aluminum-magnesium-silicon (Al-Mg-Si) alloys are the most widely used alloys in the aluminum extrusion industry. These alloys are classified as the AA 6000 series. Alloys in this series are known for their good extrudability, good corrosion resistance, good weldability, and moderate strength, as well as for their low cost [13-18]. Alloys of the 6000 series make up $80 \%$ of extruded products, and $70 \%$ of these alloys are AA $6063[19,20]$. Temperature increases are due to the friction force that occurs during extrusion of the material. Parameters such as shape change resistance, billet temperature and length, extrusion speed, and mold temperature determine the temperature increase. These temperature increases reduce the surface quality of the product and also cause a coarse-grained microstructure [21, 22]. Optimization of the extrusion parameters and also application of processes such as cooling and homogenization are needed in order to control these temperature increases. With the finite element method, an optimum geometry can be obtained in the design of an industrial product that addresses many different current applications $[23,24]$. To prevent design problems in pipe fittings, a belted design geometry was developed for the stress regions [23]. The goal of research related to the industrial design has been to achieve an ideal design geometry. A new universal method called DMROVAS (design method requiring optimum volume and safety) was proposed to find the optimum design parameters of a tibial component [24]. All safety and stress analyses of the geometries for this design were carried out using the ANSYS program. Apart from the analysis of design geometries using finite element models, many different metallurgical properties have been examined using ANSYS $[25,26]$. No research has been found in the literature studies regarding the change of microstructure and mechanical properties resulting from the cooling rate of auto parts.

The front suspension silent block is used for chassis connection, especially in high-speed vehicles such as Audi and Volkswagen. Automobile silent block material can be produced by casting, injection, and powder metallurgy method. Powder metallurgy production costs are very high. Although the casting method's cost is cheap, the mechanical properties are much lower than desired [13, 14]. Extrusion method is the most ideal method for this geometry according to injection. It is also a plastic forming method, and its mechanical properties are therefore better [25, 26]. A product has been reported to an industrial organization as having insufficient mechanical properties at high speeds. Water cooling has been recommended by the Bilecik S. E. University Metallurgy and Materials Engineering Department to solve this problem. The effect of cooling on the mechanical properties of the AA 6063 alloy produced by the extrusion method was investigated, and the microstructural and mechanical properties were evaluated using the ANSYS program. For this purpose, an automobile silent block part with regions differing in thickness and width was cooled in an air and a water environment after the extrusion process with the aim of improving the mechanical and microstructural features. Afterwards, samples were prepared from different sections of the products cooled by the two methods. Microhardness measurements and tensile tests were carried out, and engineering stress-strain curves were drawn. The microstructure of the samples was then examined with an optical microscope, and chemical analyses were performed via an electron microscope. Finally, safety coefficients and stress amounts were calculated in the ANSYS program using the finite element method. Thus, the effects of the cooling environment and regional cooling were examined.

\section{Materials and Methods}

In this study, the Ay-De aluminum extrusion line, which produces automobile spare parts, was used. In the experimental studies, two AA 6063 quality aluminum silent block parts were produced, and one was water-cooled and the other air-cooled after extrusion. The most important alloying elements of AA 6063 are magnesium and silicon. The chemical composition of this material is given by weight $\%$ in Table 1 . Since the silent block part under examination 
TABLE 1: AA 6063 aluminum alloy chemical composition.

\begin{tabular}{ccccccc}
\hline $\mathrm{Mg}$ & $\mathrm{Si}$ & $\mathrm{Fe}$ & $\mathrm{Cu}$ & $\mathrm{Zn}$ & $\mathrm{Cr}$ & $\mathrm{Mn}$ \\
\hline 0.51 & 0.43 & 0.35 & 0.09 & 0.012 & 0.01 & 0.01 \\
\hline
\end{tabular}

had areas differing in thickness and width, samples were taken from three different regions of the products cooled using the two methods. This front suspension silent block is given schematically in Figure 2, and the sampled regions are indicated. The samples were cooled by air and water at three different cooling rates. Thus, there were six different test samples in three different dimensions (Table 2). Figure 3 shows the graph with the heating and cooling process.

The samples were sanded with the 200-1200 mesh sandpaper, respectively, until the surface scratches had disappeared. The surfaces were then polished with $9 \mu \mathrm{m}$ and $6 \mu \mathrm{m}$ diamond paste, followed by $1 \mu \mathrm{m}$ alumina in preparation for etching. These samples were etched in a solution prepared by adding $30 \mathrm{~mL}$ of caustic soda $(\mathrm{NaOH})$ to $70 \mathrm{~mL}$ of water and waiting for $4 \mathrm{~min}$, after which the samples were ready for microstructural examination. The microstructures of the samples taken from different regions were examined under a Nikon L135 optical microscope. In order to represent the microstructure of the entire piece, the images prepared for each region were taken in different magnifications. In addition, the average grain sizes were calculated. In the experiments, a Shimadzu HMV-2 hardness measuring device capable of applying loads of $98 \mathrm{mN}-120 \mathrm{~N}$ was used for micro-Vickers hardness measurements. The microhardness test was performed by applying a load of HV-0.5 $(500 \mathrm{~g})$ for $10 \mathrm{~s}$. This experiment was repeated five times, and all results were averaged. Samples taken from the parts were processed in a way to facilitate tensile testing on CNC benches. These samples were then subjected to tensile testing.

\section{Results and Discussion}

3.1. Microstructure and EDS Results. The peaks obtained as a result of the energy dispersive X-ray (EDX) analysis applied using scanning electron microscopy (SEM) are given in Figure 4 . In the chemical analysis results, the aluminum ratio varied between $99.27 \%$ and $98.98 \%$, while the magnesium ratio varied in the range of 0.50 to $0.68 \%$ and silicon from 0.21 to $0.40 \%$ (Table 3 ). The variation in these rates is an acceptable result (Table 1); i.e., the change in the mechanical properties was not caused by a chemical difference. According to these results, the change occurring in the mechanical tests of the different samples is a proof that the cooling type and regional cooling were the causes of the change.

The microstructure images of the AA 6063 quality aluminum alloy samples taken from the parts cooled with air and water following the extrusion process are shown in Figure 5. When the microstructure images are examined, different grain sizes are seen. The air-cooled samples have grain sizes of $150-165 \mu \mathrm{m}$, whereas the grains of the watercooled ones are $18-25 \mu \mathrm{m}$. This was a result of the cooling rate differences because when the cooling rate is slow, it leads to slow nucleation and large grain size $[13,14,27]$. Consequently, cooling with water can result in a particle size six times smaller than that can be obtained with air cooling.

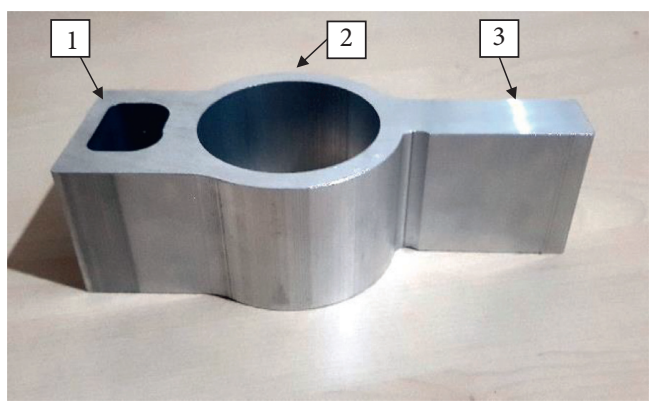

FIGURE 2: Regional schematic representation of the extrusion piece.

TABLE 2: Labeling of samples.

\begin{tabular}{lccc}
\hline Sample name & Thickness (A) & Length (B) & Cooling type (C) \\
\hline 1 & 10 & 20 & Air \\
2 & 7.5 & 50 & Air \\
3 & 25 & 60 & Air \\
4 & 10 & 20 & Water spray \\
5 & 7.5 & 50 & Water spray \\
6 & 25 & 60 & Water spray \\
\hline
\end{tabular}

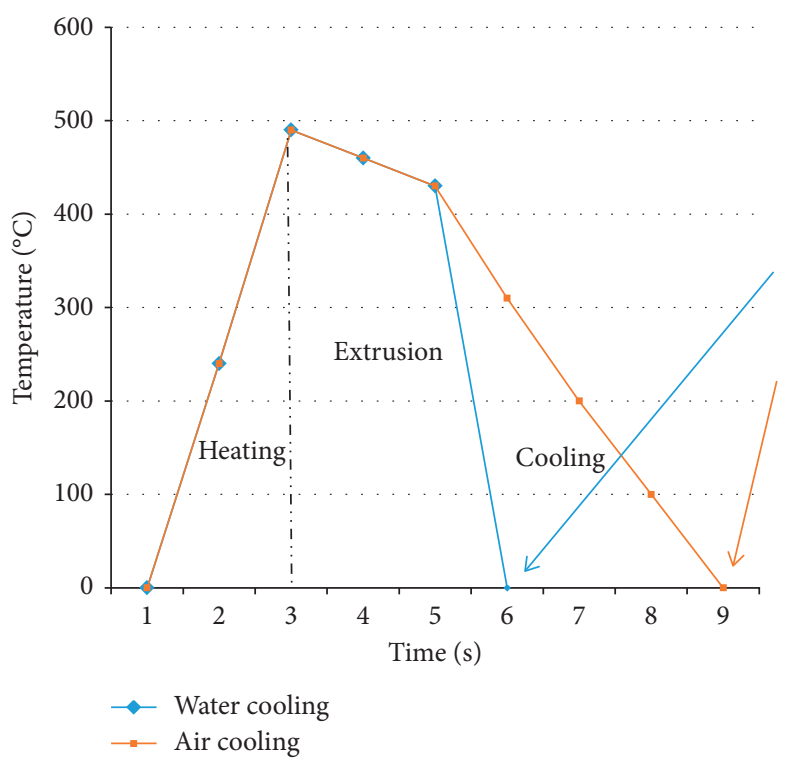

FIgURE 3: Heating and cooling process.

3.2. Tensile Test and Hardness Measurement Results. After the extrusion process, the microhardness measurement results of the samples of different cross sections of the parts that were cooled in air and water environments are given in Table 4. When the measurement results are examined, a relationship is seen between grain size and hardness. Fine grains were obtained, and high hardness values were measured with rapid cooling. This was because smaller precipitates were formed or more magnesium and silicon atoms formed solid solutions. The results obtained are similar to those of studies in the literature [11-15]. It was observed that the hardness values increased by $25 \%$ on average by rapid cooling of the AA 6063 alloy after extrusion. As a result, it can be said that mechanical properties were affected by the different cooling rates. 


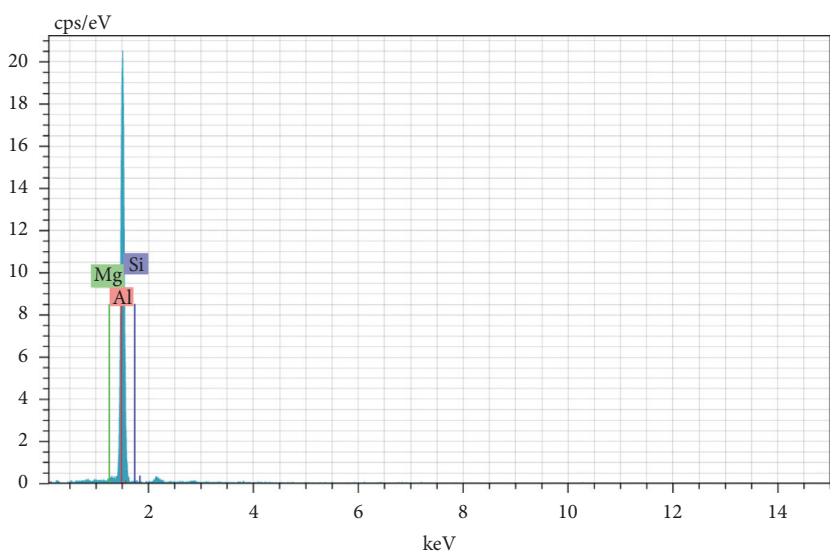

FIGURE 4: Peaks of the EDS analysis performed via an electron microscope.

TABLE 3: Results of EDS analysis (\%).

\begin{tabular}{lcccccc}
\hline \multirow{2}{*}{ Element } & \multicolumn{5}{c}{ Sample no. } & \\
& 1 & 2 & 3 & 4 & 5 \\
\hline Aluminum & 99.27 & 99.19 & 99.15 & 99.00 & 99.15 & 98.98 \\
Magnesium & 0.50 & 0.55 & 0.54 & 0.68 & 0.59 & 0.62 \\
Silicon & 0.23 & 0.21 & 0.31 & 0.32 & 0.26 \\
\hline
\end{tabular}

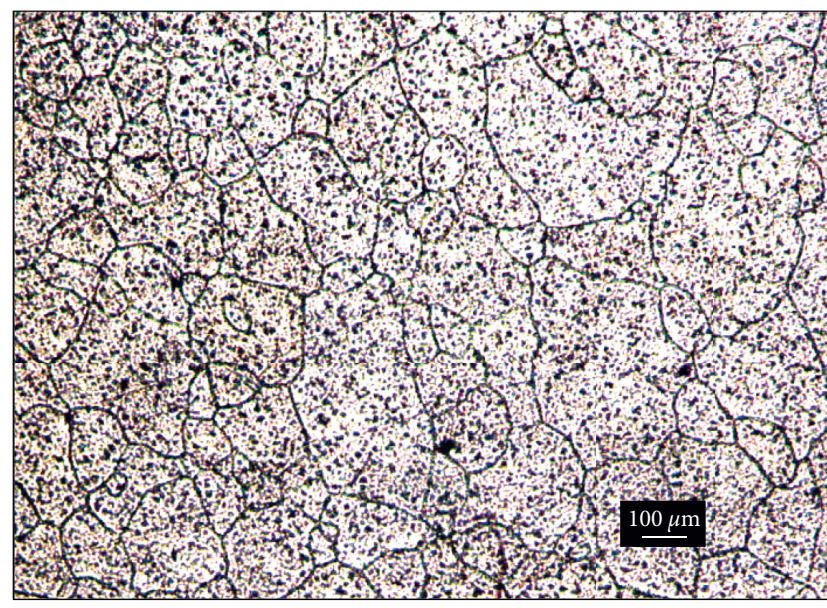

(a)

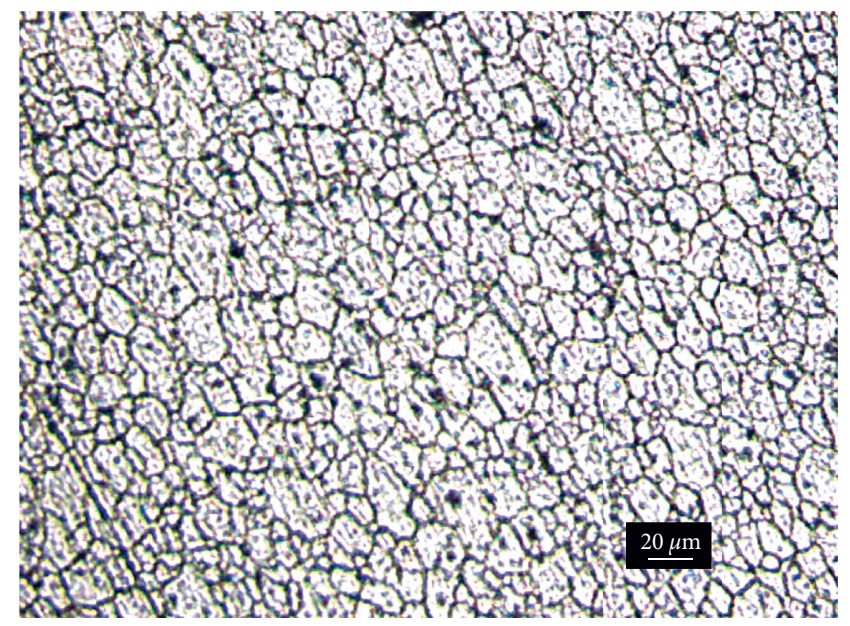

(b)

Figure 5: Microstructure images after extrusion: (a) air cooling and (b) water cooling.

TABLE 4: Vickers hardness values of samples cooled in air and water after extrusion.

\begin{tabular}{lcccccc}
\hline Measured sample & 1 & 2 & 3 & 4 & 5 & 6 \\
\hline Microhardness (HV) & 80 & 95 & 82 & 96 & 99 & 91 \\
\hline
\end{tabular}

The tensile test results of the samples of different cross sections of the parts which were simultaneously cooled in air and water after the extrusion process are given in Table 5.
TABLE 5: Tensile test results of samples cooled after extrusion.

\begin{tabular}{lcccccc}
\hline Sample name & 1 & 2 & 3 & 4 & 5 & 6 \\
\hline Tensile strength $(\mathrm{MPa})$ & 218 & 223 & 202 & 248 & 284 & 236 \\
Yield strength $(\mathrm{MPa})$ & 180 & 205 & 155 & 220 & 240 & 210 \\
\hline
\end{tabular}

Upon examination of the measurement results, a relationship was found between grain size and tensile strength. With rapid cooling, fine grains were obtained, and high strength values were measured (Figure 6). 


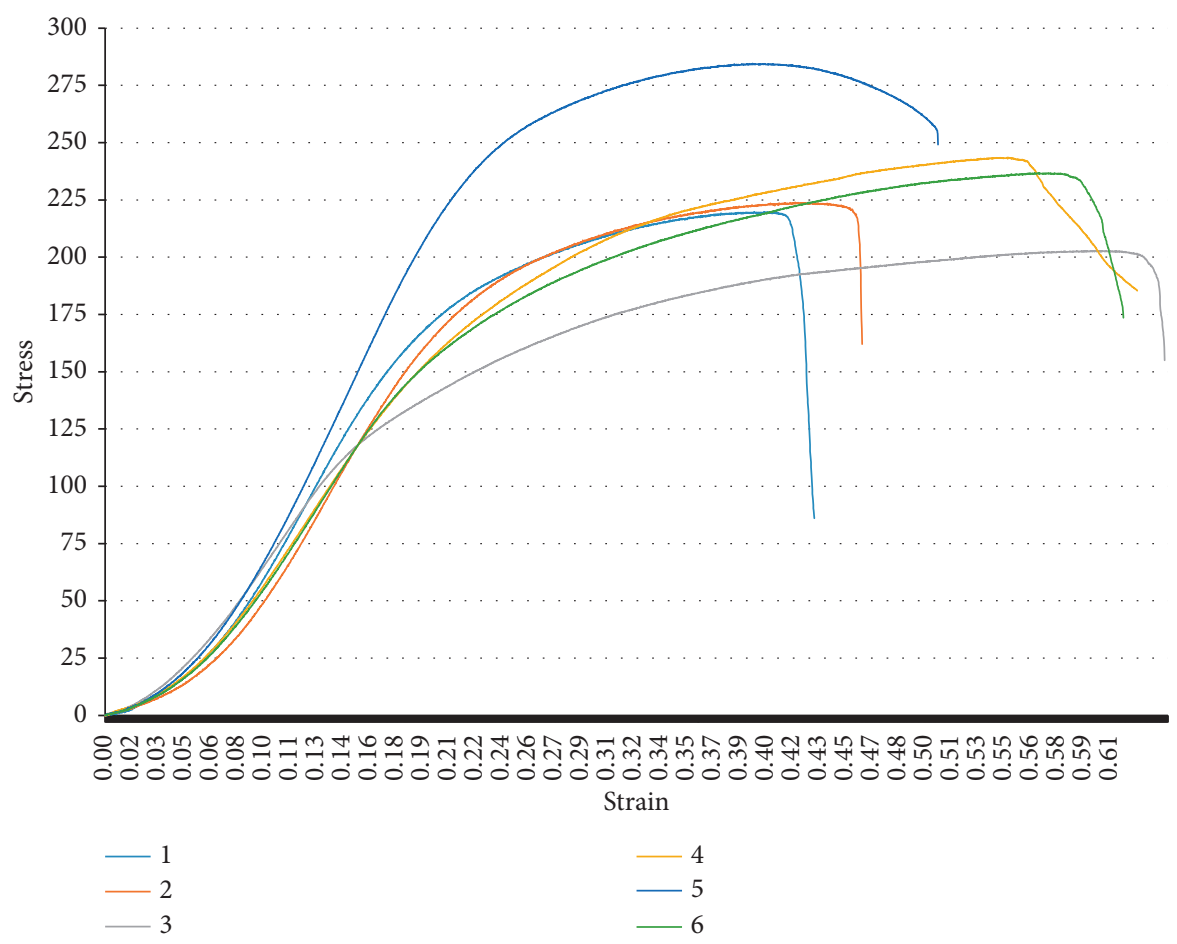

Figure 6: Engineering stress-strain curves from tensile testing of samples: (a) 1, (b) 2, (c) 3, (d) 4, (e) 5, and (f) 6.

3.3. Evaluation of the Effect of Cooling Speed on the Safety Coefficient via Finite Element Analysis (FEM). The finite element method (FEM) was used in the ANSYS-Workbench program to model the effects on the safety coefficient of the variations in mechanical properties found in different regions on the silent block connection. The forces and fixing process are shown in Figure 7. The lower part was fixed, and $50,000 \mathrm{~N}$ force was applied in three different regions $[3,4]$.

For mesh generation, a Solid187 tetrahedron element was used in the whole finite element model. A convergence analysis with mesh sizes from $2 \mathrm{~mm}$ down to $1 \mathrm{~mm}$ was accomplished. In our study, the maximum equivalent stresses on the plate and the maximum error energy were considered as convergence criteria. $\vartheta$ was the volume of the element, $\{\Delta \sigma\}$ was the nodal stress error, $e$ was the error energy in element $i$, and $\{D\}$ was the stress-strain matrix. The nodal stress error $\{\Delta \sigma\}$ was the averaged nodal stresses minus the unaveraged nodal stresses $[28,29]$ :

$$
e_{i}=\frac{1}{2} \int \vartheta\{\Delta \sigma\}^{T}[D]^{-1}\{\Delta \sigma\} d \vartheta .
$$

The material properties are defined in the library according to the region considering three different cooling rates. In line with the A-A section in Figure 7, probes were assigned to 50 different node points, and as a result, a graph was obtained for the distribution of the safety coefficient on the surface. As a result, the front suspension silent block part produced by aluminum extrusion using two different production methods (air-cooled and water-cooled) was analyzed via FEM. The curves of the safety coefficients are given in Figure 8.

When looking at the results, greater stress amounts were found at the corner points of the part. Looking at this result, it can be said that stress was effective in the corners. The stress values formed in the air- and water-cooled parts differed. Since the mechanical properties in the water-cooled part were better, a lower amount of stress was found. It was observed that the mechanical properties of the AA 6063 alloy were increased by an average of $25 \%$ by rapid cooling after extrusion. This result indicated that mechanical properties were affected by the different cooling rates. Regarding these safety coefficient results, the minimum safety coefficient for the water-cooled part was $62 \%$ higher than that for the aircooled part. According to this, with the change in the process, the safety coefficient was increased by a high rate. Moreover, the highest coefficient of safety values in the aircooled product ranged from 7 to 7.5 , while these values were increased in the air-cooled product from 10 to 12 . It was determined that this production method would promote safer driving, especially under difficult road conditions at high speeds. Moreover, the most likely result is that this product will prolong fatigue life.

There were three different variable parameters on the silent block connection part: width/thickness (A), length (B), and cooling type (C). The changes in these parameters on the surface plot chart are given in Figure 9. When these results are examined, the geometry of the short part $(\mathrm{A})$ is more effective for hardness change than that of the long part (B). However, parameter B is more effective in the change of breaking strength since it affects the hardness change. The cooling type, on the other hand, affects hardness and tensile strength at a higher gradient than the long part, and determines these results at a slightly lesser gradient than the short part. The thinness of the narrow and wide sections shows that the cooling rate is already an 


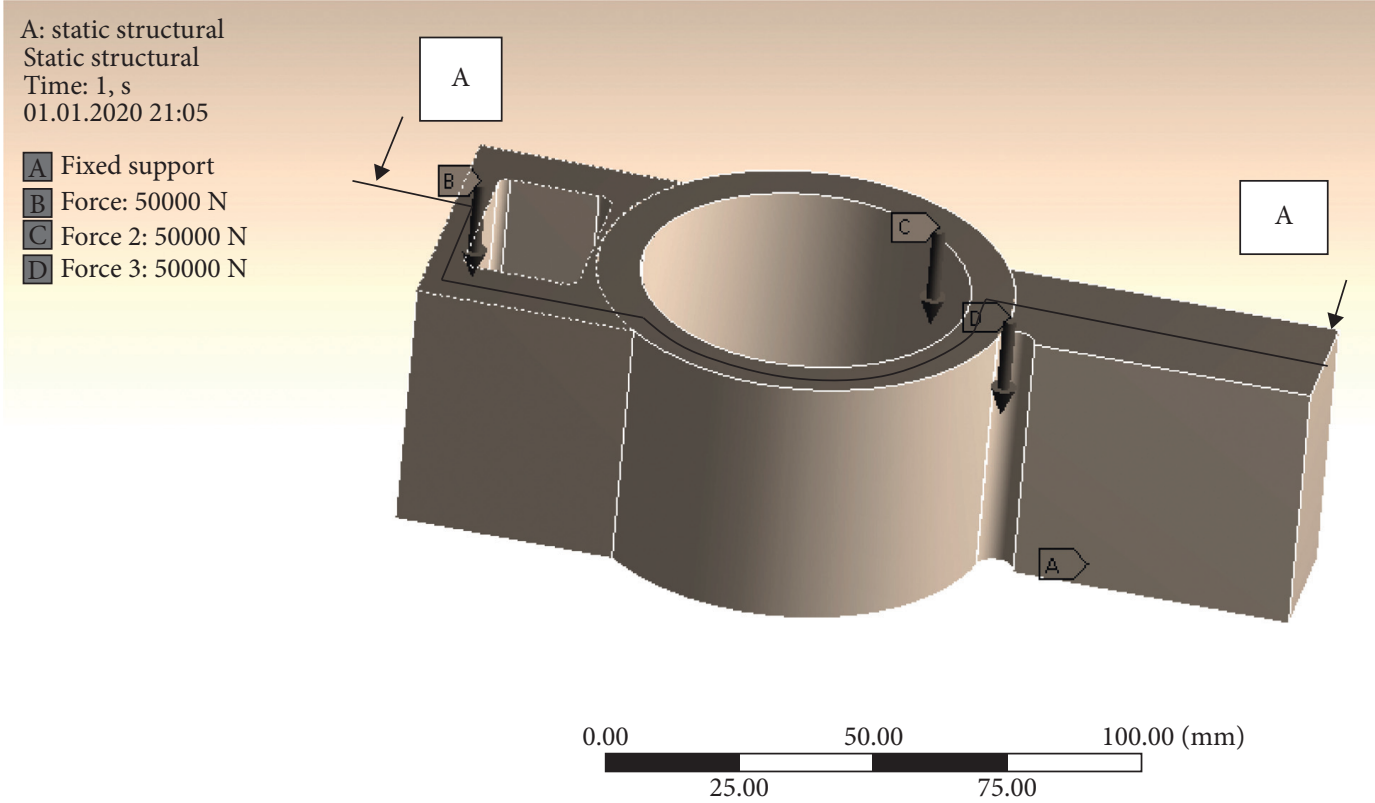

FIgURE 7: Fixed surface and applied forces for the finite element method to section A-A.

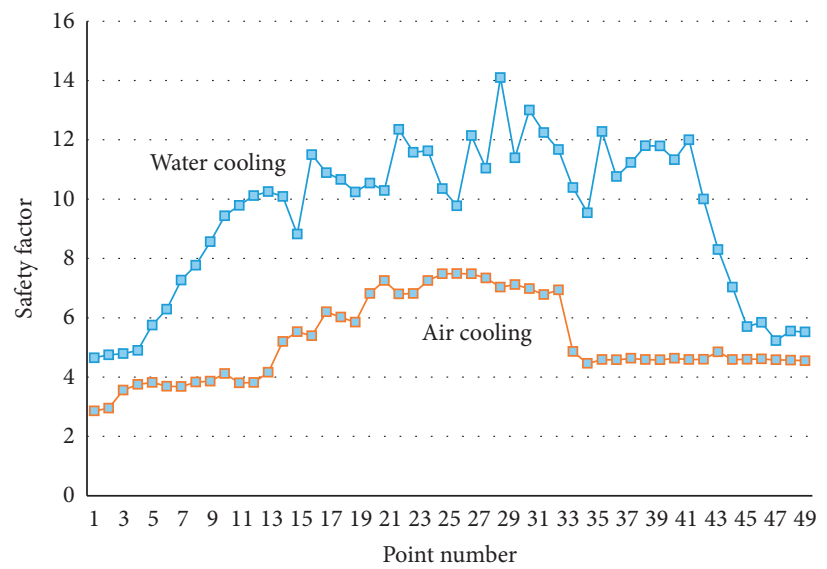

Figure 8: Safety coefficient curve of the water-cooled part.

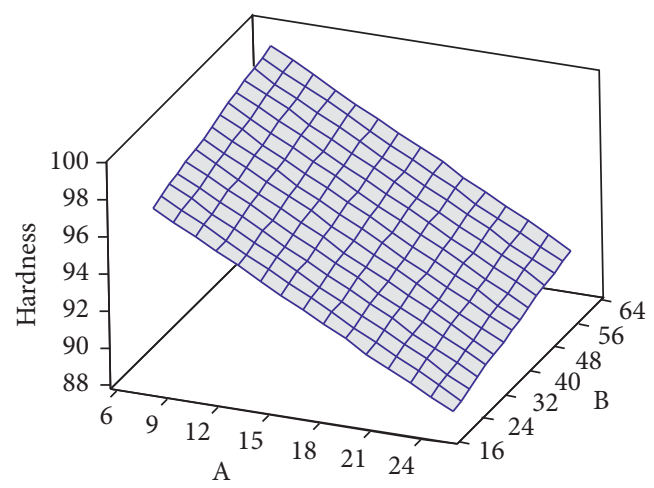

(a)

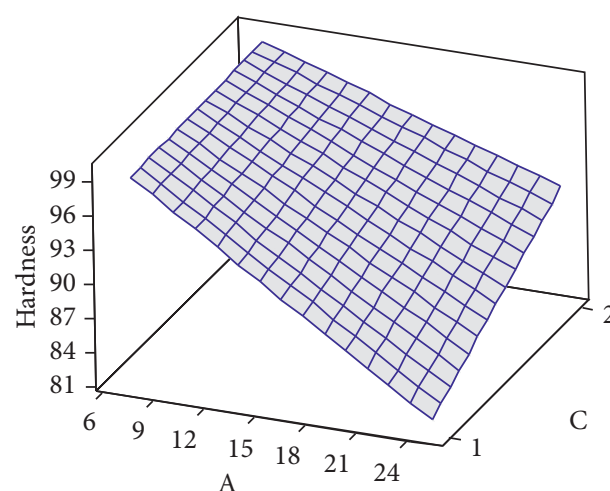

(b)

Figure 9: Continued. 


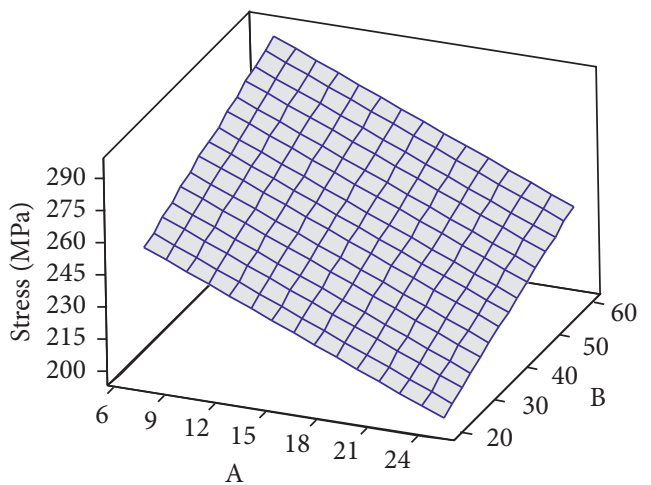

(c)

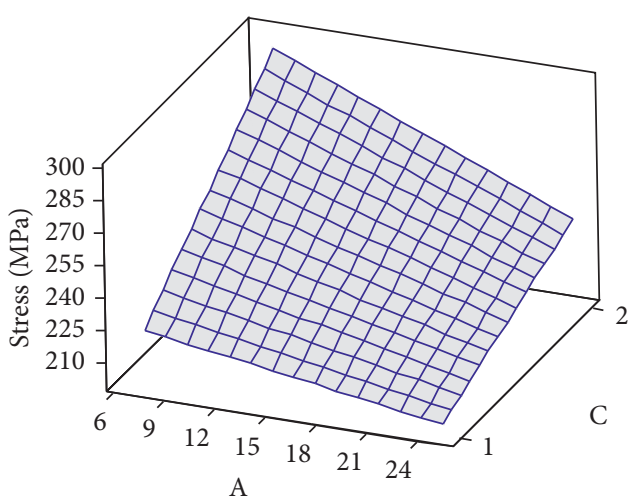

(d)

Figure 9: Production parameters of tensile strength and hardness change with related surface plot graphics.

important factor. In addition to this, hardness and breaking strength increase when the cooling rate is increased rapidly.

\section{Conclusions}

The front suspension silent block for chassis connection on new-generation vehicles allows high-speed driving. An industrial organization has determined that these products exhibit inadequate mechanical properties. The Bilecik S. E. University Metallurgy and Materials Engineering Department has recommended the use of water cooling to solve this problem, and as a result of this process, microstructural and mechanical properties were evaluated via the ANSYS program. The effects of the cooling environment and regional cooling on the mechanical properties of the AA 6063 alloy produced by the extrusion method were investigated, and the following conclusions were drawn:

When the mechanical values of different areas of a silent block produced from the AA 6063 aluminum alloy were measured, it was determined that the values differed regionally. This was because this part had areas that varied in thickness and width. This resulted in rapid cooling in regions having a thin cross-sectional area and slow cooling in areas with a thick cross-sectional area.

The mechanical values of the AA 6063 aluminum alloy were increased with water cooling after extrusion. This is an indication that the secondary phase particles became finer with rapid cooling.

The average grain size of the AA 6063 aluminum alloy increased with air cooling after extrusion. This is an indication that nucleation decreased with slow cooling. The mechanical values of the AA 6063 aluminum alloy increased by about $25 \%$ with rapid cooling after extrusion.

Chemically, no remarkable difference was observed in the AA 6063 aluminum alloy samples with either air or water cooling after extrusion. This is an indication that the mechanical differences were not caused by chemical changes.
The minimum safety coefficient values of the air-cooled samples were lower than those of the water-cooled samples because the mechanical properties were lower than in the water-cooled samples.

When the amount of stress was examined, it was seen that the stress was greater in the corners of the part.

The amount of stress of the parts cooled by air and by water appeared to differ, which could have resulted from the mechanical differences.

\section{Data Availability}

The data used to support the findings of this study are available within the article or from the corresponding author upon request.

\section{Conflicts of Interest}

The authors declare that they have no conflicts of interest.

\section{Acknowledgments}

The authors would like to thank the "AYDE Alüminyum San. ve Tic. A.Ș." company, which allowed them to use the production line to perform the extrusion process in this research.

\section{References}

[1] H. Hatekar, B. Anthonysamy, V. Saishanker, L. Pavuluri, and G. S. Pahwa, "Silent block bush design and optimization for pick-up truck leaf spring," SAE Technical Paper 2017-01-0455, SAE International, Warrendale, WA, USA, 2017.

[2] J. Ziobro, "Analysis of suspension element of car body on the example silentblock," Advances in Science and Technology Research Journal, vol. 9, no. 28, pp. 125-129, 2015.

[3] E. Yelkencioğlu, "Control of camber angle in planar five arm suspension system," Master's thesis, İstanbul Technical University, Institute of Science, İstanbul, Turkey, 2009.

[4] H. Kutlak and İ. Uygur, "Fatigue life analysis of a commercial vehicle sheet metal wishbone system by using finite element method," Duzce University Journal of Science and Technology, vol. 2, no. 1, pp. 235-250, 2014. 
[5] A.I. Fedotov, D. A. Tikhov-Tinnikov, and V. S. Baradiev, "Simulation of process of functioning silent blocks of car suspension," Advances in Engineering Research, vol. 158, pp. 135-140, 2018.

[6] L. Kunchev, N. Pavlov, and G. Yanachkov, "Mechanicmathematical modeling of independent suspension as take account elasticity of silent blocks," International Scientific Journal Machine Technologies Materials, pp. 29-35, 2010.

[7] R. Lefanti, M. Ando, and J. Sukumaran, "Fatigue and damage analysis of elastomeric silent block in light aircrafts," Materials \& Design (1980-2015), vol. 52, pp. 384-392, 2013.

[8] P. K. Saha, Aluminium Extrusion Technology, ASM International-The Materials International Society, Cleveland, $\mathrm{OH}$, New York, 2000.

[9] A. M. Jorge Jr., M. M. Peres, J. B. Fogagnolo, C. S. Kiminami, C. Bolfarini, and W. J. Botta, "Hot extrusion of nanostructured al-powder alloys: grain growth control and the effect of process parameters on their microstructure and mechanical properties," Metallurgical and Materials Transactions A, vol. 40, Article ID 3314, 2009.

[10] W. C. Chen, C. H. J. Davies, I. V. Samarasekera, J. K. Brimacombe, and E. B. Hawbolt, "Mathematical modeling of the extrusion of 6061/Al2O3/20p composite," Metallurgical and Materials Transactions A, vol. 27, no. 12, pp. 4095-4111, 1996.

[11] H.-J. Hu, "The effects of process parameters on evolutions of thermodynamics and microstructures for composite extrusion of magnesium alloy," Advances in Materials Science and Engineering, vol. 2013, Article ID 259594, 9 pages, 2013.

[12] H. Aydın, M. Şendeniz, and A. H. Demirci, "Influence of heat treatments before and after extrusion on the mechanical properties of AA 6063 aluminium alloy," Uludağ University Journal of The Faculty of Engineering, vol. 14, no. 2, pp. 1-10, 2009.

[13] B. Öztürk, "Energy consumption model for the pipe threading process using 10 wt.- $\% \mathrm{Cu}$ and 316L stainless steel powderreinforced aluminum 6061 fittings," Materials Testing, vol. 61, no. 8, pp. 797-805, 2019.

[14] B. Öztürk, "Experimental research of energy consumption of austenitizing heat-treated casting fittings in pipe threading," Sakarya University Journal of Science, vol. 23, no. 5, pp. 869-878, 2019.

[15] B. Öztürk and Ö. Küçük, "Specific energy consumption (SEC) model for types of two different production of fittings which is reinforced by chip of copper and brass," Journal of Polytechnic, vol. 23, no. 1, pp. 27-35, 2020.

[16] R. K. Behera, B. P. Samal, S. C. Panigrahi, and K. K. Muduli, "Microstructural and mechanical analysis of sintered powdered aluminium composites," Advances in Materials Science and Engineering, vol. 2020, Article ID 1893475, 7 pages, 2020.

[17] B. Öztürk and F. Kara, "Calculation and estimation of surface roughness and energy consumption in milling of 6061 alloy," Advances in Materials Science and Engineering, vol. 2020, Article ID 5687951, 12 pages, 2020.

[18] A. Ambroziak, M. Korzeniowski, P. Kustroń, M. Winnicki, P. Sokołowski, and E. Harapińska, "Friction welding of aluminium and aluminium alloys with steel," Advances in $\mathrm{Ma}$ terials Science and Engineering, vol. 2014, pp. 1-15, 2014.

[19] R. A. Siddiqui, H. A. Abdullah, and K. RAl-Belushi, "Influence of aging parameters on the mechanical properties of 6063 aluminium alloy," Journal of Materials Processing Technology, vol. 102, no. 1-3, pp. 234-240, 2000.

[20] M. Şendeniz, "Investigation of property changes of a selected Al-Mg-Si alloy (AlMgSi0.5: Etial 60) with heat treatments,"
Master's thesis, Uludağ University, Institute of Science, Bursa, Turkey, 2006.

[21] W. H. Van Geertruyden, H. M. Browne, W. Z. Misiolek, and P. T. Wang, "Evolution of surface recrystallization during indirect extrusion of 6xxx aluminum alloys," Metallurgical and Materials Transactions A, vol. 36, no. 4, pp. 1049-1056, 2005.

[22] S. Turenne, F. Ajersch, N. Legros, and S. Laplante, "Mechanical behavior of aluminum matrix composite during extrusion in the semisolid state," Metallurgical and Materials Transactions A, vol. 30, no. 4, pp. 1137-1146, 1999.

[23] Ö. Küçük and B. Öztürk, "Development of design geometry of aluminum fittings for healthy and safety sanitary installations," Journal of Environmental Protection and Ecology, vol. 18, no. 2, pp. 776-787, 2017.

[24] B. Öztürk and F. Erzincanli, "Development of femoral component design geometry by using DMROVAS (design method requiring optimum volume and safety)," Engineering Computations, vol. 37, no. 2, pp. 682-704, 2019.

[25] W. Zhao, Z. Sun, Z. Tang et al., "ANSYS-Based simulation and optimization on temperature field of amorphous ingot made by water quenching," Metallurgical and Materials Transactions A, vol. 45, no. 5, pp. 2371-2375, 2014.

[26] M. F. Urbano, "Study of the influence of inclusions on the behavior of NiTi shape-memory alloys in thermal cycling by means of finite element method," Metallurgical and Materials Transactions A, vol. 43, no. 8, pp. 2912-2920, 2012.

[27] D. Dışpınar, M. Uluda, and L. Gemi, “A356 alaşiminda katilaşma hizi ve sivi durumda bekletme süresinin mekanik özellikler üzerine etkisi," in Proceedings of the 4th International Symposium on Innovative Technologies in Engineering and Science, pp. 1752-1758, Pecs, Hungary, September 2016.

[28] A. Steinbrück, M. Woiczinski, P. Weber, P. E. Müller, V. Jansson, and C. Schröder, "Posterior cruciate ligament balancing in total knee arthroplasty: a numerical study with a dynamic force controlled knee model," Biomedical Engineering Online, vol. 13, no. 1, pp. 1-13, 2014.

[29] E. Calisal and L. Ugur, "Evaluation of the plate location used in clavicle fractures during shoulder abduction and flexion movements: a finite element analysis," Acta of Bioengineering and Biomechanics, vol. 20, no. 4, pp. 41-46, 2018. 